\title{
Correlation of the Vitamin Requirements with Cultural and Biochemical Characters of Lactobacillus spp.
}

\author{
By M. ROGOSA \\ National Institute of Dental Research, National Institutes of Health, Public Health \\ Service, U.S. Department of Health, Education and Welfare, \\ Bethesda, Maryland, U.S.A. \\ J. G. FRANKLIN AND K. D. PERRY* \\ National Institute for Research in Dairying, The University of Reading, \\ Shinfield, Reading, England \\ (Received 24 January 1961)

\section{SUMMARY} \\ Improved media are described for the study of the vitamin requirements of a \\ wide range of Lactobacillus spp., some of which had not previously been grown \\ consistently well. In general, the nutritional data are consistent within species and \\ corrclate well with the other differentiating characteristics of species. Also, the \\ nutritional requirements were in agreement with results obtained with several \\ species some years ago. Improved or abundant growth, not achieved in previous \\ studies with several other species, resulted from the use of the more nearly optimal \\ media developed in the present study. The growth of $L$. bulgaricus was prevented \\ or inhibited by folic acid at $10 \mu \mathrm{g} . / 1$.
}

\section{INTRODUCTION}

Since the pioneer work of Snell \& Strong (1939) on the assay of riboflavin with Lactobacillus casei var. rhamnosus (American Type Culture Collection, ATCC 7469) microbiological methods have come into general use for the determination of several other essential nutrilites. Indeed, in some instances, as in the measurement of biotin, folic acid and vitamin $\mathbf{B}_{12}$ in low-potency foodstuffs, no convenient alternative method is yet available. The accumulation of a large literature on the nutrition of the lactic acid bacteria has quickened an awareness of the complexity of nutritional interrelationships essential for enzymic activity, growth and its inhibition. An excellent, brief but comprehensive, survey of this subject was made by Snell (1952).

It has become increasingly apparent that requirements for essential metabolites, under carefully standardized optimal conditions, generally are characteristic for the species of a genus, even though sometimes an individual strain may behave exceptionally. For instance, Fildes (1923, 1924) differentiated members of the genus Haemophilus on the basis of their requirements for the ' $\mathrm{X}$ ' and ' $\mathrm{V}$ ' factors. More recently, in an extensive study of the genus Bacillus, Knight \& Proom (1950) and Proom \& Knight (1955) showed that the requirements for vitamins and amino acids

* Present address: The Dairy Research Institute (N.Z.), Palmerston North, New Zealand. 
were closely correlated with other species characteristics. Rogosa, Tittsler \& Geib (1947) found a very high correlation of vitamin requirements with cultural and biochemical characteristics within the genus Lactobacillus. With $\mathbf{5 0 0}$ oral strains Rogosa et al. (1953) confirmed the results of a previous study (Rogosa et al. 1947) by again finding a high degree of correlation between nutritional requirements and the cultural and biochemical characteristics of species. However, certain species could not be tested for nutritional requirements because they were not cultivatable in any of the media then used; some of these organisms even may grow poorly and erratically in present-day widely used media. Among these species were L.bulgaricus, L. lactis, L. helveticus, L. jugurti, L. acidophilus, L. delbrueckii and L. leichmanii (Tittsler, Rogosa \& Whittier, 1942; Rogosa et al. 1947). Except for L. acidophilus, these have not been regularly isolated from human or animal oral samples.

As a consequence of expanding knowledge, media for assay purposes have become plentiful, but media developed for specific assays with specific organisms may not be generally applicable for a wide range of species. The purpose of the present work, therefore, was to devise a medium suitable for the optimal growth of a number of species which grew poorly or not at all in any media used in earlier nutritional tests. Furthermore, since some species have already been systematically studied, an attempt has been made to determine the stability of their nutritional requirements and then the reliability of this character as a useful adjunct in the correlation of characteristics required for the adequate and realistic differentiation of species.

\section{METHODS}

Media. The composition of the basal medium used is shown in Table 1.

The solution of vitamin-free acid-hydrolysed casein (Table 1) was prepared from the product of Allen and Hanbury's Ltd., or from the 'vitamin-free, salt-free' casein hydrolysate (acid) of the Nutritional Biochemicals Corporation, by the method of Ford, Perry \& Briggs (1958). Various charcoals (e.g. Norit A, Darco G60, the Grade 5 activated charcoal of Sutcliffe and Speakman Ltd.) were satisfactory. Additions of the cyclic amino acids, DL-tryptophan, L-tyrosine, DL- $\beta$-phenylalanine, L-proline and L-histidine were made exactly as indicated by Ford et al. (1958).

\section{Table 1. Composition of the 'complete' basal medium}

Solution of vitamin-free acid-hydrolysed casein (see text)

Solution of vitamin-free pancreatic casein digest (see text)

Glucose

$\mathrm{K}_{2} \mathrm{HPO}_{4} ; \mathrm{KH}_{2} \mathrm{PO}_{4}$

$\left(\mathrm{NH}_{4}\right)_{2} \mathrm{HC}_{6} \mathrm{H}_{5} \mathrm{O}_{7}$

Ascorbic acid

Cysteine $\mathbf{H C l}$

Tween 80

Quantities per litre final medium.

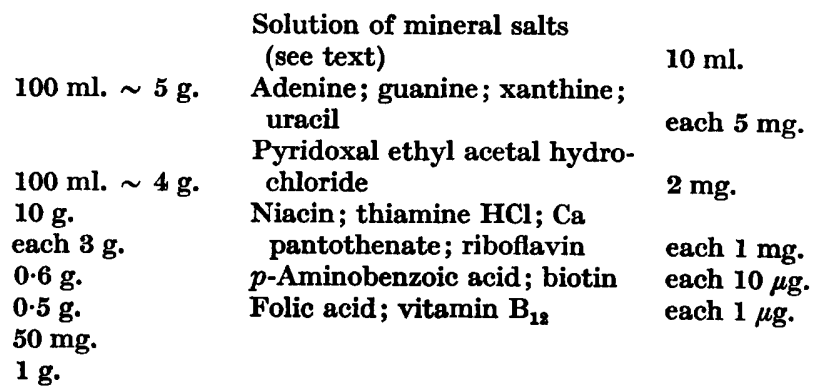

Adjusted to pH 6.0-6.1 before addition of the required vitamins. Brought to final volume 1 1. with distilled water. 
The pancreatic digest of vitamin-free casein (Table 1) was prepared according to Roberts \& Snell (1946); it was used at a concentration of solids equivalent to 4. g./l. final medium. Both the acid-hydrolysed and pancreatic digests of casein were kept frozen until required.

Adenine, guanine, and uracil were dissolved in boiling distilled water acidulated with just sufficient $\mathrm{HCl}$ to effect solution. Xanthine was dissolved in boiling water, solution being aided by adding a minimum of $10 \%(\mathrm{w} / \mathrm{v}) \mathrm{NaOH}$ solution. These solutions were made up to $0.5 \mathrm{mg} . / \mathrm{ml}$. and were kept at $5^{\circ}$.

Solids such as glucose, the phosphates, di-ammonium citrate, ascorbic acid and cysteine $\mathrm{HCl}$ were weighed out and added as needed for each fresh batch of medium. Sodium acetate was not added in this way because the casein digest solutions already contained acetate as a result of the prescribed adjustments of $\mathrm{pH}$ value with acetic acid and sodium or potassium hydroxide, and thus contributed a calculated $0.6 \%$ $(w / v)$ of anhydrous sodium or potassium acetate to the final medium. Refrigerated Tween 80 was warmed and added directly as the final medium was being prepared.

The solution of mineral salts used in the medium (Table 1) was that of Ford et al. (1958).

The concentrations of vitamin solutions in $20 \%(\mathrm{v} / \mathrm{v})$ ethanol in water were as follows: $p$-aminobenzoic acid, nicotinic acid, thiamine $\mathrm{HCl}$, pyridoxal ethyl acetal $\mathrm{HCl}, \mathrm{Ca} \mathrm{D}$-pantothenate, all $1 \mathrm{mg} . / \mathrm{ml}$.; riboflavin, $100 \mu \mathrm{g} . / \mathrm{ml}$. and vitamin $B_{12}$, $5 \mu \mathrm{g} . / \mathrm{ml}$. (each with 1 drop of concentrated $\mathrm{HCl}$ ); DL-biotin and folic acid at $100 \mu \mathrm{g} . /$ ml. in $20 \%(\mathrm{v} / \mathrm{v})$ ethanolic $1 \%(\mathrm{w} / \mathrm{v}) \mathrm{NaHCO}_{3}$. These solutions were kept at $5^{\circ}$ in the dark and any necessary dilutions were made only when final media were prepared. Any excess of a diluted solution was discarded.

The media were dispensed in $10 \mathrm{ml}$. quantities into $6 \times \frac{5}{8}$ in. rimless test tubes, capped with Oxoid aluminium caps, and heated in racks in the autoclave to $115^{\circ}$. Immediately on reaching this temperature the autoclave was turned off. Only fresh media were used and first inoculations were generally made immediately on cooling and never into media more than one day old.

Inoculation. Actively growing cultures passed through three successive transfers in MRS medium (de Man, Rogosa \& Sharpe, 1960) were used. Inocula of 1 drop were taken directly from such cultures or from suspensions of organisms washed twice in saline. Both methods gave identical results. Three serial transfers were made into the test media.

Incubation and examination. Except for Lactobacillus casei, L. plantarum, L. buchneri, L. cellobiosus, L. viridescens and $L$. brevis, which were incubated at $30^{\circ}$, all tubes were incubated at $37^{\circ}$ for about $18 \mathrm{hr}$. Visual observations of growth in each serial transfer were recorded and the optical density of the third serial transfer was also measured in tubes of $\frac{5}{8}$ in. diameter in a Hilger Biochem Absorptiometer equipped with filter $61(610 \mathrm{~m} \mu)$.

\section{RESULTS AND DISCUSSION}

Descriptions of the Lactobacillus spp. are in general agreement in studies by OrlaJensen (1919, 1943), Rogosa et al. (1953), Sharpe (1955), Wheater (1955 $a, b)$ and Rogosa \& Sharpe (1959). The cultural and biochemical characteristics of every strain included in the present work are known and have been repeatedly determined by one or often all of the above authors. Where group antisera were available 
(Sharpe, 1955), the serological characteristics are also known. Therefore, except where it may be necessary in order to clarify certain relationships, detailed data about the general non-nutritional behaviour of the species will not be given. Certain general nutritional results, also, will not appear in the tables. For example, nicotinic acid and pantothenic acid were indispensable for the growth of all species. Exogenously supplied thiamine was required by all the heterofermentative species and by none which are homofermentative. These results are in entire agreement with those of Rogosa et al. (1953) and of Koser \& Fisher (1950). Folinic acid and $p$ aminobenzoic acid were not essential or stimulatory for any species. Biotin requirements were not investigated because of the nature of the basal medium (Table 1) required for the good growth of a variety of species.

The nutritional requirements of Lactobacillus casei and L. plantarum found were the same as recorded previously by Rogosa et al. (1953). All the variant strains of L. case $i$ required added folic acid and pyridoxal whereas $L$. plantarum grew well in their absence. Rogosa et al. (1953) stated that vitamin $B_{6}$ (pyridoxal) was essential for the growth of some strains of $L$. casei and that there was 'severe limitation of growth in absence of added substrate' with others. The present results are therefore in excellent agreement with previous work, and because of the high correlation with other characteristics, one may differentiate with confidence between $L$. casei and $L$. plantarum on the basis of nutritional results combined with a few other data. The essential differentiating data are shown in Table 2. All strains of these species grew abundantly in the medium containing the full complement of vitamins; after incubation for $18 \mathrm{hr}$. the optical density values of the turbid cultures were generally at least 1.3 and often were 1.7 or more.

There are 8 known homofermentative species which cannot grow at relatively low temperatures $\left(15^{\circ}\right)$ and which nearly always grow at $45^{\circ}$ or higher. These belong to the group designated Thermobacterium Orla-Jensen $(1919,1943)$. The detailed serological and physiological criteria by which they may be distinguished were described by Rogosa \& Sharpe (1959). Until recently the distinction between Thermobacterium bulgaricum Orla-Jensen (1919, 1943), i.e. Lactobacillus bulgaricus, and Thermobacterium jugurt Orla-Jensen (1919, 1943) syn. Lactobacillus jugurti Rogosa \& Sharpe (1959), was not clear. These species were confused by Bergey's Manual (1948, 1957), Rogosa et al. (1953), Wheater (1955a, b) and Sharpe (1955). However, de Man (1956, 1960) isolated a sufficient number of strains of $L$. bulgaricus which conformed with Orla-Jensen's original description, thus enabling de Man to differentiate clearly between this species and $L$. jugurti and L. helveticus. Rogosa \& Sharpe (1959), who used de Man's strains and some other isolates, confirmed entirely the results of de Man $(1956,1960)$ and Orla-Jensen $(1919,1943)$. A study of the vitamin requirements of these organisms has now shown that a similar differentiation is also possible by this method; pyridoxal is essential for the growth of $L$. jugurti and $L$. helveticus but not for $L$. bulgaricus.

Lactobacillus helveticus differs from $L$. jugurti only in fermenting maltose (OrlaJensen, 1919, 1943) and dextrin (Wheater, 1955 a); but similar or the same enzymes are involved in the fermentations of these $\alpha$-D-glucosides. The organisms are serologically identical, and produce distinctively large amounts of DL-lactic acid. The nutritional data support the view that these organisms are closely related species, since both organisms have identical requirements. There may be some 


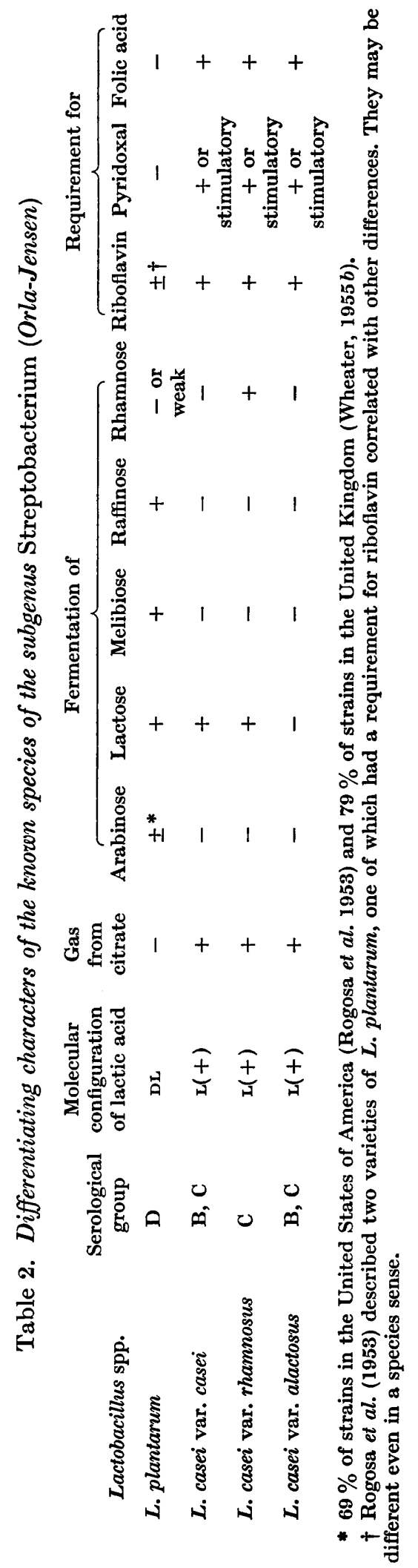


merit in the proposal of de Man (1956) to unite these species under the name L. helveticus emend.

Lactobacillus bulgaricus and $L$. lactis possess some common features, particularly the same group antigen and the ability to produce equivalent amounts of $D(-)$ lactic acid in milk; but $L$. lactis differs in fermenting maltose, sucrose and salicin (Rogosa \& Sharpe, 1959). L. lactis grew profusely, whereas L. bulgaricus grew poorly or not at all in the complete medium (Table 1). Under these circumstances, when poor delayed growth occurred with $L$. bulgaricus, erratic and non-reproducible requirements were exhibited. Modifications of the medium in Table 1, such as the addition of lactose, pyridoxal phosphate, riboflavin phosphate and pantetheine improved growth. But the media were still unsatisfactory for L. bulgaricus; growth was poor and unpredictable from small inocula and sometimes tended to improve with each serial transfer. It was obvious that adaptation to unfavourable conditions was taking place with time. When the strains of $L$. bulgaricus were eventually induced to grow through repeated subcultivation, most of the erratic requirements disappeared and the single riboflavin requirement resembled that of $L$. lactis (Table 3). Folic acid at $10 \mu \mathrm{g} . / 1$. completely prevented the growth of many strains of $L$. bulgaricus and it was necessary to decrease the folic acid content to $1 \mu \mathrm{g} . \Lambda$. or to eliminate it entirely. Folinic acid at $10 \mu \mathrm{g}$./1. also was toxic. These difficulties were not encountered with $L$. lactis in the medium of Table 1 ; further work on the nutrition of $L$. bulgaricus is required.

Lactobacillus lactis differs from $L$. acidophilus, generally, in the quantity of acid produced in milk and in the different configurations of the lactic acids produced. L. acidophilus ferments amygdalin and cellobiose and quenches the fluorescence of aesculin, while $L$. lactis does not (Rogosa \& Sharpe, 1959). The vitamin nutrition of these organisms is also different: $L$. acidophilus exhibited a requirement for folic acid which was not shown by $L$. lactis (Table 3).

Table 3. Some nutritional requirements of the subgenus Thermobacterium Orla-Jensen

\begin{tabular}{|c|c|c|c|c|c|}
\hline Lactobacillus spp. & Riboflavin & Pyridoxal & Folic acid & $\begin{array}{c}\text { Vitamin } \\
\mathbf{B}_{12}\end{array}$ & Thymidine \\
\hline$L_{\bullet}$ helveticus & + & + & - & - & - \\
\hline L. jugurti & + & + & - & - & - \\
\hline L. bulgaricus & + & - & - & - & - \\
\hline L. lactis & + & - & - & $-*$ & - \\
\hline L. acidophilus & + & - & + & $-*$ & - \\
\hline L. leichmannii & - & - & + & $\begin{array}{c}+ \text { or } \\
\text { stimulatory } \dagger\end{array}$ & - \\
\hline L. delbrueckii & + & - & - & - & + \\
\hline L. salivarius & + & - & + & - & - \\
\hline
\end{tabular}

$+=$ requirement; $-=$ no exogenous requirement.

* Some strains exhibit erratic requirements under highly aerobic conditions, particularly in the absence of certain deoxyribosides.

$\dagger$ In absence of deoxyribosides.

On the basis of fermentation tests alone it may be difficult to distinguish between Lactobacillus acidophilus and L. leichmannii, the only difference being the fermentation of galactose by the former but not by the latter. Apart from this property, 
and the production of DL-lactic acid by $L$. acidophilus and $\mathrm{D}(-)$ lactic acid by $L$. leichmannii (a determination which may not be routinely easy for some laboratories), the only other consistently unambiguous differentiating property is the formation of acid in milk by $L$. acidophilus. However, all the strains of $\boldsymbol{L}$. acidophilus tested required riboflavin whereas $L$. leichmannii did not (Table 3). Thus, an organism which exhibits the characters described by Rogosa \& Sharpe(1959) could be correctly placed in one or other of these species by a titration of the acidity produced in milk and by the presence or absence of a riboflavin requirement.

Lactobacillus delbrueckii and L. leichmannii, although alike in producing $\mathbf{D}(-)$ lactic acid in suitable media and in not fermenting lactose in milk, are distinctly different in their action on aesculin and in the fermentation of cellobiose, salicin and trehalose (Rogosa \& Sharpe, 1959). They also exhibited consistent differences in their nutritional behaviour. Whereas $L$. delbrueckii required riboflavin + thymidine, but not folic acid or vitamin $\mathbf{B}_{12}$, L. leichmannii required folic acid + vitamin $\mathbf{B}_{12}$ but not riboflavin or thymidine (Table 3 ). It would be desirable to have information about more than the four available strains of $L$. delbrueckii; unfortunately strains so named and received from other workers very often proved to be members of other species. This small number of strains within a species is unusual since many species have been represented by a large number of strains, sometimes hundreds, in repeated studies by the present authors and others.

Lactobacillus salivarius (Rogosa et al. 1953) possesses a new group antigen and is otherwise distinct from other species. Although the vitamin requirements of I. acidophilus were the same as those of $L$. salivarius, these species are consistently different morphologically, serologically, in the fermentation of cellobiose, mannitol and sorbitol, and usually behave differently in melibiose, raffinose, rhamnose and salicin (Rogosa \& Sharpe, 1959).

The status of the heterofermentative species of the genus Lactobacillus is more uncertain and may reflect a higher degree of variability. The general characteristics of $L$. fermenti, L. buchneri, L. brevis, L. cellobiosus and $L$. viridescens have been described either by Orla-Jensen (1919, 1943), or in Bergey's Manual (1948, 1957), or by Rogosa et al. (1953) and Rogosa \& Sharpe (1959). Of these species, only L. fermenti has the Group F antigen (Sharpe, 1955), grows at $45^{\circ}$ and not at $15^{\circ}$, and typical strains do not ferment arabinose $(\mathbf{7 9} \%)$ and xylose $(\mathbf{7 7} \%)$.

Lactobacillus brevis and $\boldsymbol{L}$. buchneri are related antigenically but also, peculiarly, have the same group antigen as $L$. lactis (Sharpe, 1955). Eighty-eight \% of the L. brevis strains fermented arabinose and xylose, whereas all the strains of $\boldsymbol{L}$. buchneri fermented arabinose, with only $12 \%$ fermenting xylose. Nearly all strains of both species (88-100\% in different tests) fermented $\alpha$-methyl-D-glucoside; but with many other carbohydrates there seems to be even greater variation in the behaviour of individual strains (Rogosa \& Sharpe, 1959). However, despite these disconcerting variations, $L$. buchneri and $L$. brevis can be differentiated by means of the information already given and that shown in Table 4. In our experience with several hundred strains of $L$. brevis and $L$. buchneri, the former has consistently required folic acid for growth and has not fermented melezitose, while $L$. buchneri has not required folic acid and has fermented melezitose.

Lactobacillus cellobiosus may be recognized from the descriptions given by Rogosa et al. (1953) and Rogosa \& Sharpe (1959), and by the information given in Table 4. 


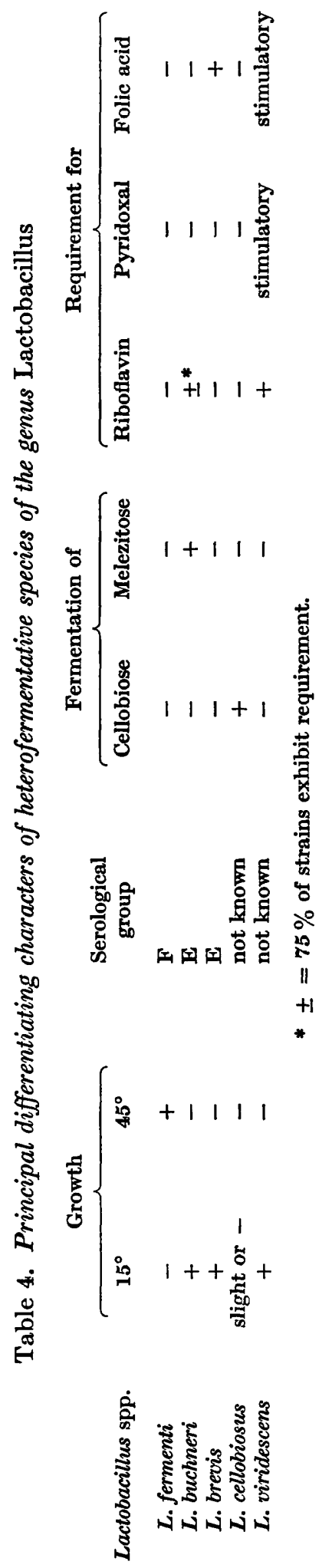


L. viridescens (Niven \& Evans, 1957) was further described by Rogosa \& Sharpe (1959) and the vitamin requirements of Table 4 conform to the original description.

With most of the organisms the vitamin requirements were sharp and unequivocal and in the absence of a required vitamin there was generally slight or no growth even in the first serial subculture. It was of particular interest that, in instances where only tentative or presumptive results had been obtained by other methods, predictions of the species identities from the nutritional data were made with a high degree of accuracy. Also, with the species, which were capable of growing well in any of the non-deficient media used, the results were in highly satisfactory agreement with those obtained some years previously. Very often, especially in examinations of a large number of isolates from similar sources, certain strains are encountered which are alike but do not conform exactly to the characteristics of any recognized species. For example, in recent work on lactobacilli from silage, Keddie (1959) isolated a number of strains which differed from known strains of Lactobacillus plantarum in consistently failing to ferment structurally dissimilar carbohydrates such as maltose and mannitol. The strains clearly belonged to the subgenus Streptobacterium Orla-Jensen and 'resembled' L. plantarum more closely than L. casei. Consequently Keddie concluded that they should be attached to the former species. Later, when representative strains kindly supplied by Dr R. M. Keddie were examined by us for their nutritional requirements it was found that they had heterogeneous requirements including, in some instances, a requirement for folic acid not previously found for any $L$. plantarum isolate. The differences in nutritional behaviour among his strains suggest that these strains are not $L$. plantarum but rather comprise a new species. It has been our repeated experience that the nutritional data often serve to emphasize the heterogeneity of certain groupings where different species have been grouped together.

We do not suggest immutability and there are well known instances whereby media and experimental conditions may influence nutritional requirements or growth antagonisms. There is the example described by Ford et al. (1958) in which Streptococcus bovis exhibited a number of nutritional requirements when cultivated aerobically, although anaerobically the organism grew well in the absence of any added vitamin. The interrelation between pyridoxine and alanine was noted by Snell \& Guirard (1943), and Griffin \& Racker (1955) showed that the $\mathrm{CO}_{2}$ requirement of Neisseria gonorrhoeae could be replaced by hypoxanthine, uracil and oxalacetate. These are only a few of the examples which can be cited; they serve to emphasize the caution which must be exercised. It is advisable not to generalize beyond the restrictions of specific experimental conditions, and in determining the optimal conditions for the growth of a significant number of strains of representative species. From this viewpoint, nutritional studies have been very helpful in the taxonomic study of the lactobacilli and have sometimes disclosed problems for further study, such as the unknown mechanism of inhibition of the growth of Lactobacillus bulgaricus by folic acid.

Much of the work described in this paper was done while one of the authors (M.R.) was a guest in the Bacteriology Department, National Institute for Research in Dairying (University of Reading), Shinfield, Reading, England. Grateful acknowledgement is made to Dr M. Elisabeth Sharpe and to Dr J. E. Ford for many helpful discussions. 


\section{REFERENCES}

Bergey's Manual of Determinative Bacteriology (1948). 6th ed. Ed. R. S. Breed, E. G. D. Murray \& A. P. Hitchens. Baltimore: Williams and Wilkins.

Bergey's Manual of Determinative Bacteriology (1957). 7th ed. Ed. R. S. Breed, E. G. D. Murray \& N. R. Smith. Baltimore: Williams and Wilkins.

Findes, P. (1923). The classification of haemoglobinophilic bacteria, based upon their relation to blood-pigment and to the 'vitamine' factor. Brit. J. exp. Path. 4, 265.

Fildes, P. (1924). The growth requirements of haemolytic influenza bacilli, and the bearing of these upon the classification of related organisms. Brit. J. exp. Path. 5, 69.

Ford, J. E., Perry, K. D. \& Briggs, C. A. E. (1958). Nutrition of lactic acid bacteria isolated from the rumen. J. gen. Microbiol. 18, 273.

Griffin, P. J. \& RACKer, E. (1955). Replacement of the carbon dioxide requirement of Neisseria gonorrhoeae by hypoxanthine, uracil and oxalacetate. Bact. Proc. p. 114.

KEDDIE, R. M. (1959). The properties and classification of lactobacilli isolated from grass and silage. J. appl. Bact. 22, 403.

Knight, B. C. J. G. \& Proom, H. (1950). A comparative survey of the nutrition and physiology of mesophilic species in the genus Bacillus. J. gen. Microbiol. 4, 508.

Koser, S. A. \& Fisher, B. J. (1950). Vitamin requirements of oral lactobacilli. J. dent. Res. 29, 760.

MAN, J. C. DE (1956). De eigenschappen van einige stammen van Bacterien behorende tot het geslacht Thermobacterium Orla-Jensen. Ned. melk- en Zuiveltijdschr. 10, 190.

Man, J. C. DE (1960). Lactobacillus bulgaricus (Luerssen et Kühn) Holland. Antonie van Leeurwenhoek J. Microbiol. Serol. 26, 77.

Man, J. C. De, Rogosa, M. \& Sharpe, M. E. (1960). A medium for cultivation of lactobacilli. J. appl. Bact. 23, 130.

Niven, C. F. \& Evans, J. B. (1957). Lactobacillus viridescens nov.spec., a heterofermentative species that produces a green discoloration of cured meat products. $J$. Bact. 73, 758 .

Orla-Jensen, S. (1919). The Lactic Acid Bacteria. Copenhagen: Andr. Fred. Host and Son.

Orla-Jensen, S. (1943). The Lactic Acid Bacteria. Copenhagen: Ejnar Munksgaard.

Proom, H. \& Knight, B. C. J. G. (1955). The minimal nutritional requirements of some species in the genus Bacillus. J. gen. Microbiol. 13, 474.

Roberts, E. C. \& SNell, E. E. (1946). An improved medium for microbiological assays with Lactobacillus casei. J. biol. Chem. 163, 499.

Rogosa, M. \& Sharpe, M. E. (1959). An approach to the classification of the lactobacilli. J. appl. Bact. 22, 329.

Rogosa, M., Titrsler, R. P. \& Geib, D. S. (1947). Correlation of vitamin requirements and cultural and biochemical characteristics of the genus Lactobacillus. J. Bact. 54, 13.

Rogosa, M., Wiseman, R. F., Mitchell, J. A., Disraely, M. N. \& Beaman, A. J. (1953). Species differentiation of oral lactobacilli from man including descriptions of Lactobacillus salivarius nov.spec. and Lactobacillus cellobiosus nov.spec. J. Bact. 65, 681.

Sharpe, M. E. (1955). A serological classification of lactobacilli. J. gen. Microbiol. 12, 107.

SNELL, E. E. (1952). The nutrition of the lactic acid bacteria. Part II. In Symposium on the lactic acid bacteria, by R. P. Tittsler, C. S. Pederson, E. E. Snell, D. Hendlin \& C. F. Niven, Jun. Bact. Rev. 16, 235.

SNELl, E. E. \& GuIrard, B. M. (1943). Some interrelationships of pyridoxine, alanine and glycine in their effect on certain lactic acid bacteria. Proc. nat. Acad. Sci., Wash., 29, 66.

Sneld, E. E. \& Strong, F. M. (1939). A microbiological assay for riboflavin. Industr. Engng Chem. (Anal.), 11, 346.

Tittsler, R. P., Rogosa, M. \& Whittier, E. O. (1942). The nomenclature and characteristics of the Lactobacillus employed for the microbiological assay of riboflavin. J. Bact. 43, 56.

Wheater, D. M. (1955a). The characteristics of Lactobacillus acidophilus and Lactobacillus bulgaricus. J. gen. Microbiol. 12, 123.

WheATER, D. M. $(1955 b)$. The characteristics of Lactobacillus plantarum, L. helveticus and L. casei. J.gen. Microbiol. 12, 133. 